\title{
Thick Oxide Coatings Formed by Spark Anodizing of Mg-Al Alloy in Alkaline Phosphate-Silicate Electrolytes
}

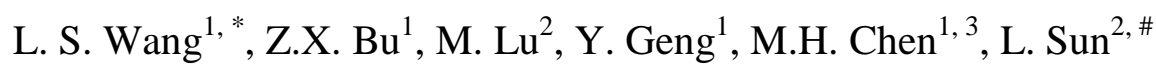

\begin{abstract}
Anodic coatings formed by spark anodizing (SA) with different electrolyte recipes often have distinct composition and properties. In this paper we report on the study of correlations between electrolytes and the coating properties of a thick SA layer $(190 \mu \mathrm{m})$ formed on an AZ91D magnesium alloy. The voltage transient during this SA process in phosphate-silicate electrolyte solution is characterized by an abrupt anodic voltage drop after initial voltage increase, followed by a stabilized voltage plateau
\end{abstract}


during which the microdischarge noise is completely suppressed. Microstructure investigations show that the cross-section of such SA thick coating contains three distinctive regions. In terms of composition, the outer layer contains uniform distribution of $\mathrm{P}$ and $\mathrm{Si}$, and the middle and inner layers are dominated by $\mathrm{Mg}$ and $\mathrm{O}$. Correspondingly, microstructures of these regions are also different, the inner layer with a cellular band and barrier structure is much more compact comparing to the middle layer. The individual thickness ranges for the cellular band and barrier regions are $500 \mathrm{~nm}-2 \mu \mathrm{m}$ and $100-600 \mathrm{~nm}$ and their individual micro-hardness reaches about $3 \mathrm{GPa}$ and $8 \mathrm{GPa}$ respectively.

\section{Introduction}

Using spark anodizing (SA) to form the protective layer on magnesium and its alloys can be dated back to W.F. Higgins when he used $\mathrm{NH}_{4} \mathrm{HF}_{2}$ solution to produce a skin of $\mathrm{MgF}_{2}$ on magnesium after an anodizing treatment. The passivated surface fluoride formed a uniform and dense protective surface layer for inner magnesium [1]. Then this fluoride anodized coating technique was modified by H.A. Evangelides in 1951 to obtain surface coatings with improved hardness [2]. This so-called H.A.E process was quickly developed into the Dow17 and other high voltage processing methods [3]. More recent SA studies on magnesium and its alloys have been focused areas including the development diluted and environmental friendly electrolyte solutions, higher treatment voltage with modified waveform, electric polarity switching and pulse frequency adjustment[4, 5]. As one of the fast growing research and development fields, there are extensive researches on the SA processing procedures as well as coating formation mechanism. Researches in such areas can be classified into two categories mainly based on the electrolytes being used. The first group focuses on investigating the influence of individual electrolyte ingredient on coating formation. For example, McNeil and Gruss studied the anodic film growth of $\mathrm{Mg}$ in a $0.1 \mathrm{M}$ $\mathrm{Na}_{2} \mathrm{WO}_{4} \cdot 2 \mathrm{H}_{2} \mathrm{O}, 0.1 \mathrm{M} \mathrm{NaAlO}_{2}$ and $0.1 \mathrm{M} \mathrm{Na} \mathrm{SiO}_{3} \cdot 9 \mathrm{H}_{2} \mathrm{O}$ aqueous electrolyte under below and above the spark potential. They found that the spark reaction products were 
dominated by noncrystalline structure with small amount of crystalline $\mathrm{MgAl}_{2} \mathrm{O}_{4}$, $\mathrm{MgO}$, and $\mathrm{Mg}_{2} \mathrm{SiO}_{4}[6,7]$. Huber studied the anodizing of magnesium in a $1 \mathrm{M} \mathrm{NaOH}$ and determined the correlation between applied voltage and resulted film properties [8]. In the same electrolyte solution, Mizutani and Kim found that the surface layers obtained at $80 \mathrm{~V}$ on magnesium and magnesium alloys had a higher corrosion rate than those formed at $10 \mathrm{~V}$ but lower than those formed at $3 \mathrm{~V}$ [9]. Jong and Okido studied the electrochemical properties and formation mechanism of anodic oxides on $\mathrm{Mg}-\mathrm{Al}$ alloys and found that the concentration of $\mathrm{Mg}(\mathrm{OH})_{2}$ in formed surface layers decreased with increasing applied voltage, while the concentration of $\mathrm{MgO}$ increased [10]. Other studies carried out by Barton and Johnson showed the effects of electrolytes, including fluorides, phosphates, aluminates and tetraborates, having very different high-voltage anodization characteristics, sparking appearance, potential/current behavior and the film structures [11].

The other category of studies focused on obtaining high quality surface coating using complex electrolytes. Recently, the generation of thick SA coatings undergone a so-called "soft" spark microdischarge process began to attract increasing attention. Using this approach, Yerokhin and Currran showed that thick oxide films composed of $\mathrm{MgO}$ and $\mathrm{MgAl}_{2} \mathrm{O}_{4}$ or $\mathrm{MgAl}_{3} \mathrm{O}_{4}$ [12-14] can be formed on magnesium alloys in a Keronite-type electrolyte. Arrabal also successfully produced thick SA coatings on several magnesium substrates and confirmed the formation of the barrier layers through focused ion been (FIB) study $[15,16]$. These thick protective multilayers can provide tunable microstructures and mechanical properties that are closely related with the electrolyte composition and SA parameters $[17,18]$.

In this study, we demonstrate the synthesis of a $190 \mu \mathrm{m}$ SA thick coating on Mg-Al substrates and report on the systematic studies of the composition, morphology and microstructure of the oxide coatings using ultramicrotomy, SEM, and TEM. The study allows us to correlate the microstructure characteristics of the surface oxide to the different stages of the SA process. 


\section{Experimental}

\subsection{Materials}

The AZ91 alloy substrates used in this study were prepared by the metallic mold casting process with gas protection $\left(0.5 \% \mathrm{SF}_{6}+\mathrm{CO}_{2}\right)$. The material compositions are as follows (in wt.\%): $\mathrm{Al}$ 9.1, $\mathrm{Zn} 0.85, \mathrm{Mn} 0.27$ with $\mathrm{Mg}$ balance. Solid solution treatment was carried out in electric resistance furnace under $\mathrm{CO}_{2}$ protection, in which the specimens were heated to $420^{\circ} \mathrm{C}$ and held for $20 \mathrm{~h}$, then quenched in $20^{\circ} \mathrm{C}$ water. Samples were cut into stripes with a dimension of $50 \mathrm{~mm} \times 30 \mathrm{~mm} \times 10 \mathrm{~mm}$ and went through a sequential degreasing in ethanol, rinsing in deionized water and drying in warm air treatment. Before SA, the samples were masked with lacquer (45-stopping off lacquer, Macdermid Plc) to define a treatment area. This exposure area is $1.7 \mathrm{~cm}^{2}$ for all samples.

\subsection{Spark anodizing procedure}

The masked AZ91D samples were as anodes and a stainless steel plate was as the cathode. In this study, the aqueous phosphate-silicate electrolyte contains $\mathrm{Na}_{4} \mathrm{P}_{2} \mathrm{O}_{7}$ $(5-20 \mathrm{~g} / \mathrm{L}), \mathrm{Na}_{2} \mathrm{SiO}_{3}(5-20 \mathrm{~g} / \mathrm{L})$, and $\mathrm{KOH}(0.5-1.5 \mathrm{~g} / \mathrm{L})$. The SA process took place in a $1000 \mathrm{ml}$ double-walled glass cell in which a cooling water/glycol mixture was circulated in the jacket layer to maintain the electrolyte temperature close to $35^{\circ} \mathrm{C}$. Here the SA treatment was conducted using a square waveform (negtive to positive current density ratio, $J_{\mathrm{c}} / J_{\mathrm{a}}=1.3$ ) generated by an ACS-FB power supply (ET Systems Electronic $\mathrm{GmbH}$ ) at $50 \mathrm{~Hz}$ for $90 \mathrm{~min}$. The constant current density is $430 \mathrm{~mA} / \mathrm{cm}^{2}$ (rms) for all experiments. A constant current mode is used to achieve a relative stable surface oxidation rate. Current and corresponding voltage were recorded at a sampling rate of $0.1 \mathrm{~ms}$ using a SCXI controlled Labview data acquisition (National Instruments). Data were analyzed by Igor Pro (Wavemetrics) and a Tektronix TDS 2020 oscilloscope running WaveStar software. After each SA treatment, the samples were rinsed in distilled water, dried in hot air and then kept under dry environment prior to examination. 


\subsection{Surface and cross-section morphology of the thick SA coatings}

SEM cross-section samples of the SA coating were prepared by grounding with successive grades of $\mathrm{SiC}$ papers, followed by $1 \mu \mathrm{m}$ diamond paste finishing. A sputtered carbon layer was then deposited for SEM (ZEISS EVO50) examination (together with surface specimens).

\subsection{Analysis of the Interface area between the coating and Mg substrate}

TEM samples were prepared by unltramicrotomy (Leica Ultracut). Polishing oil was used as $\mathrm{Mg}$ slices collection instead of water to reduce bulk Mg oxidation (polishing oil was self-made and diluted). After the collection, a layer of carbon was sputter deposited on the unltramicrotomy block for SEM (ZEISS EVO 50) investigation and the collected Mg slices were sent to TEM (JEOL 2000 II ) examination.

Micro-hardness measurements were performed on the polished cross-section of the samples using a nano-indenter (MTS Nano Indenter XP). The indents were distributed evenly across the interface between coating and substrate, and the distance between adjacent indents was $1 \mu \mathrm{m}$.

\subsection{Phase identification of the thick SA coating}

Phase analysis of the oxide films was performed using a Philips X'Pert-APD (PW 3710) X-ray diffractometer, using $\mathrm{CuK} \alpha$ radiation (at $50 \mathrm{kV}$ and $40 \mathrm{~mA}$ ), at a scanning speed of $0.005^{\circ} / \mathrm{sec}$ with a scan range between 5 to $85^{\circ}$ (in $2 \theta$ ). X-ray can penetrate the entire oxide layer to provide diffraction data through the layer thickness.

\section{Results}

\subsection{Voltage-time response and the transition of the waveform}

Fig. 1 shows the voltage-time response with current density profile discussed above during SA. It includes four different voltage response periods in the first 10 minutes. Period I corresponds to a conventional anodizing response. In period II, a large number of sparks in the form of moving discrete white microdischarges can be observed. In period III, there is a slow increase in the responding applied voltage and 
the microdischarge color turns from white to yellow, in the same time the sparks grew in size with a significant decrease in spatial density. In period IV, the microdischarges move at high speed and a number of light flames floating on the electrode surface can be clearly identified; accompanying the fast motion of these microdischarges is the dramatic dropping in spark noise and a significant drop in applied voltage. These visible characteristics of spark evolvement in these four periods are summarized in table 1 .

Fig. 2 shows the representative period of current-time curves taken around 2min, $3 \mathrm{~min}$, $4 \mathrm{~min}, 10 \mathrm{~min}, 25 \mathrm{~min}$, and $75 \mathrm{~min}$ into the experiment. The anodic pulse period shown in Fig. 2(a) has two maximum peak zones. Peak A corresponds to a primary corona discharge and the peak B reflects a coating breakdown. These two peak zone feature diminishes versus time, and completely disappears at about $4.5 \mathrm{~min}$ into the SA process similar to what Arrabal described in their paper [16]. The current density waveform stabilizes after about 10 minutes.

\subsection{Surface and cross-section morphology of the SA coating and element distribution}

We first look at the surface of the SA formed film. Fig.3 is a representative surface morphology image of the SA coating. Clear retained discharge channels and eruption debris can be seen in Fig.3 (a). Corresponding image acquired from the back scattering electron shows polygonal cracks and magma-like areas, as shown in Fig.3 (b).

Better understanding of the oxide microstructure and morphology comes from the cross-sectional microscopy. Fig.4 summarizes the morphology and element distribution study of the SA layer cross-section using SEM. With relatively low magnifications in this study, a three-layer sub-structure of the formed oxide layer can be identified. And here they are referred as the outer layer, the middle layer and the inner layer. Parts of the outer layer were missing due to the sample preparation. In this outer layer, through-pass pores can also be observed. The middle layer of the oxide coating contains large number of fine cracks and shows a darker contrast when compared to the outer layer. Corresponding Electron probe micro-analyzer (EPMA) 
images shown in Figs.4 (b-e) demonstrates that $\mathrm{Si}, \mathrm{P}$ from electrolyte penetrate into the outer layer while $\mathrm{O}$ is distributed evenly throughout the entire film thickness. As shown in Fig.5, such composition distribution is confirmed by line scanning analysis.

\subsection{Cross-section morphology of SA coating on unltramicrotomy block}

Fig.6 shows the macro-morphology of the unltramicrotomy block sample. The coating was partially peeled off due to the cutting impact force, which is also an indication of the relative low bonding strength for the middle layer. Bedded cracks can be observed in certain areas from Fig.6 (b), which implies the development of residual stress during coating formation.

Fig.7 shows the SEM micrographs of the oxide/substrate interface region of the sample at different magnifications. A cellular dendritic band formation can be identified adjacent to the $\mathrm{Mg}$ substrate. Small amount of cavities and cracks appear around the cellular dendritic band with no apparent preferred orientation. Higher magnification SEM pictures, as shown in Figs.7 (b-d), further reveal the detailed morphology of the fine-cellular structure and existence of thin barrier layer structure.

\subsection{Interface morphology studied by TEM}

To further reveal the oxide layer structure, TEM studies were conducted on the unltramicrotomy slices. As shown in Fig.8, with a much higher magnification than the SEM, a barrier layer (transition area) along the Mg substrate can be clearly identified. Fig.8 includes two typical TEM images of this barrier layer structure. On top of this barrier layer is a cellular dendritic structure fusing to it.

\section{5 Microhardness across the interface region}

Using nano-indentation, sample hardness across the interface was measured. Fig.9 shows the nano-indented hardness data obtained in the oxide/substrate interface region. This measurement confirms the existence of the hard thin barrier layer between the close to the Mg substrate a much softer structure, presumably, the inner layer with the cellular structure. Maximum measured barrier layer hardness can reach 8GPa. In comparison, the substrate hardness is about $1 \mathrm{GPa}$ and that of the cellular 
area is around $3 \mathrm{GPa}$. For aluminum alloys, the oxide layer hardness will reach 4-6 $\mathrm{GPa}$ after conventional anodic oxidation. If using SA processing, the oxide hardness can reach as high as $14 \mathrm{GPa}$ [18]. Our results shown here confirm this significant enhancement in oxide layer hardness resulted from the SA process in comparison with conventional anodic oxidation.

\subsection{Composition and microstructure of the thick SA coating.}

To identify the phases of the SA formed thick oxide layer, XRD analyses were conducted. As shown in Fig.10, crystalline $\mathrm{MgO}, \mathrm{SiO}_{2}$ and $\mathrm{Mg}_{2} \mathrm{SiO}_{4}$ phases are detected in addition to an amorphous background. Under the conditions of microdischarge sparking, various thermal, chemical, electrochemical and metallurgy reaction can occur $[19,20]$ :

$$
\begin{aligned}
& \mathrm{Mg} \rightarrow \mathrm{Mg}^{2+}+2 e^{-} \\
& \mathrm{Mg}^{2+}+2 \mathrm{OH}^{-} \rightarrow \mathrm{Mg}(\mathrm{OH})_{2} \\
& \mathrm{Mg}(\mathrm{OH})_{2} \rightarrow \mathrm{MgO}+\mathrm{H}_{2} \mathrm{O} \\
& \mathrm{H}_{2} \mathrm{O} \rightarrow 2 \mathrm{H}_{2}+\mathrm{O}_{2} \\
& 2 \mathrm{Mg}+\mathrm{O}_{2} \rightarrow 2 \mathrm{MgO} \\
& 2 \mathrm{MgO}+\mathrm{SiO}_{2} \rightarrow \mathrm{Mg}_{2} \mathrm{SiO}_{4}
\end{aligned}
$$

\section{Discussions}

\subsection{Effects of electrolytes on the formation of the outer layer}

Now we study the formation mechanism of the oxide layer in current SA process. For the period I discharge, there exist a number of quantitative models describing the migration and transportation of related species and the formation of SA coating. The outmost layer can be considered as quenched layer formed by the melted coating materials (see Fig.11 (a)). Meanwhile for the thicker SA coating formed during the period II microdischarge, the outer layer can be seen as an overlapping layer formed from the continuous growth of the middle and inner layer, which can be quantified by a function including the accumulation of flux to a weld pool during the submerged welding $[21,22]$. The properties of the outer oxide "slag" can play an important role 
for the inward coating growth to AZ91D substrate. Based on the nature of the anion complexes and the molten coating materials, a so-called "basicity index" (BI) can be introduced to describe the effect of different electrolyte species incorporated into the outer layer:

$$
\mathrm{BI}(\text { Basicity Index })=\frac{\sum\left(\mathrm{R}_{2} \mathrm{O}+\mathrm{RO}\right)}{\sum \mathrm{RO}_{2}}
$$

The numerator and the denominator are the individual mole fraction of the basic and acidic oxides contained in the outer layer, respectively. When the basicity index (BI) is less than 1.0, the outer layer can be considered as acidic. An index between 1.0 and 1.2 means the outer layer is close to neutral, and an index above1.2 classifies the outer layer as basic. It is expected that the higher BI value, the more oxygen consumed during the consequent metallurgical reactions. BI reflects the electrolyte viscosity, activity and thermionic emission properties of the outer layer. In this study we assume the outer layer to have a composition of $0.6 \mathrm{MgO}: 0.2 \mathrm{Al}_{2} \mathrm{O}_{3}: 0.2 \mathrm{SiO}_{2}$ (based on $\mathrm{EDX}$ result). This corresponds to a BI value of 3, which is strongly basic. This strong basic outer layer can effectively improve the distribution uniformity of colloidal microcells and particles in the molten state and results in better dispersion of the incorporated oxide clusters.

\subsection{Formation of the middle layer}

The formation of the middle layer is a result of the metal thermal oxidization under combined influences of high temperature and high electric field. When the thickness of outer layer reaches certain value, thermal dissipation will become difficult for inner material, and part of the oxide clusters embedded in the outer layer can also act as oxidation seeds and covert into active cathode spots due to the low electron emission from these metal oxides, in comparison to the alloying metal species (see Table 1). Moreover, high temperature and high electric field can help the formation of the local high energy spots $\left(10^{6} \mathrm{~A} / \mathrm{cm}^{2}\right)$ with enhancing electron emission. The escaping electrons will bomb the $\mathrm{Mg}$ substrate and cause local melting and oxidation of $\mathrm{Mg}$, as shown in Figs.11 (b) and (c). The shape of the oxidized regions is reciprocal pear or 
sphere, which was the initial shape of local middle layer. At the same time, $\mathrm{Mg}$ vapor can also be produced from the vicinity of the cathode spots and erupt with high outward velocity, which forms the through-pass channels (or pores) in the oxide layer. Further thickening of the middle layer is a result of the bi-polar electric current. A low $J_{\mathrm{c}} / J_{\mathrm{a}}$ ratio (for example, 0.7 ) will produce a direct current component, which simulates the direct current SA process and will only cause the thickening of the outer layer. With larger $J_{\mathrm{c}} / J_{\mathrm{a}}$ ratio (for example, 1.3 in this paper), the increase of the total coating thickness will mainly be originated from the middle-layer thickening. The rate limiting step during the formation process of the thick SA coating is the interface area between the outer layer and the middle layer (see Fig.11 (b)), not the interface at electrolyte/coating or coating/substrate. At this stage, the breakdown events again become less important. Also the energy consumption in this process is mainly due to the excitation, expansion and recession of the cathode spots, which transforms $\mathrm{Mg}$ into Mg oxide. The formation of the period IV microdischarges ("soft" spark) originates from the breakdown of the gas or vapor (corona discharge), which is at the slightly high voltages than that in period I (shown as the U-t curve in Fig.1). With the barrier layer inward propagating to the magnesium substrate, the conduction resistance will decrease with increasing temperature so the output voltage will exhibit an apparent drop.

\subsection{Microstructure of the inner layer}

Figs.7, 8 show the formation of the fine cellular dendritic regions (the size of a typical cellular is approximately $200-400 \mathrm{~nm}$ in diameter) which is similar to the microstructure infusion zone of a weld, forming the inner layer. Such a structure is similar to Ono's observation in morphology but with much larger size here [23]. In addition, the barrier layer here is continuous and can be considered as a transition zone, similar to the oxide film formed under the thermal effect of electron bombardment. The Mg atoms in barrier layer migrate from both the interlayer (19\%) and $\mathrm{Mg}$ substrate (81\%) to form a dense, pore-free structure. 


\section{Conclusion}

Using a "soft" sparking technique, the thickness of the oxide layer formed on $\mathrm{Mg}$ alloy substrate can be significantly increased. Such a thick SA layer consists of three easily identifiable layers with distinct morphology, and high resolution TEM studies reveals the existence of a much thinner interfacial barrier layer between the inner layer and alloy substrate. The formation of outer layer is found to be determined by the breakdown and rapid solidification of alloy and oxide during the stage of the noisy sparking. In this outer layer, Si and P from electrolyte can be found. During the initial formation of middle and inner layers, there is a stepped voltage drop accompanying by the appearance of the soft sparking. The middle and inner layer formation is the combined result of thermal and electron emission of cathode spots imbedded the outer layer. This three layer structure provides both chemical stability and especially the mechanical strength of the barrier layer that can significantly improve the performances of $\mathrm{Mg}$ based alloys. 


\section{Acknowledgement}

This work was supported by the National Science Foundation of P. R. China(No. 50901033) and Hubei Provincial Key Laboratory Green Materials for Light Industry ([2013]2-6, [2013]2-14).Also thanks to Professor Peter Skeldon and Tero, Judith for their help on TEM, XRD and Nanoindentation characterization in the University of Manchester. 


\section{Reference}

[1] E.F. Emley. Principles of magnesium technology. Pergamon Press, New York, 1966, pp. 670-735.

[2] H.A. Evangelides, Met. Finish. 7 (1951) 56-60.

[3] J.D. Lawrence. Electroplating engineering handbook (Fourth edition), Van Nostrand Reinhold Company, 1984, pp. 410-419.

[4] J.L. Chen. Studies of the plasma electrolytic oxidation coating process, the University of Sheffield, Ph. D thesis, 2013.

[5] H.S. Dong. Surface engineering of light alloys aluminium, magnesium and titanium alloys, Woodhead Publishing Limited, 2010, pp.83-180.

[6] W. McNeil, L.L. Gruss, Anodic film growth by anion deposition in aluminate, tungstate, and phosphate solutions, J. Electrochem. Soc. 110 (1963) 853-855.

[7] W. McNeil, L.L. Gruss, US Patent: 3293158 (1966).

[8] K. Huber, Anodic formation of coatings on magnesium, zinc, and cadmium, J. Electrochem. Soc. 100 (1953) 376-382.

[9] Y. Mizutani, S.J. Kim, R. Ichino, M. Okido, Anodizing of Mg alloys in alkaline solutions, Surf. Coat. Technol. 169 (2003) 143-146.

[10]S. Jong, M. Okido, The electrochemical properties and mechanism of formation of anodic oxide films on Mg-Al alloys, Bull. Korean Chem. Soc. 24 (2003) 975-980.

[11]T.F. Barton, C.B. Johnson, The effect of electrolyte on the anodized finish of a magnesium alloy, Plating \& Surface Finishing 82 (1995) 138-141.

[12]A.L. Yerokhin, A. Shatrov, V. Samsonov, P. Shashkov, A. Leyland, A. Matthews, Fatigue properties of Keronite ${ }^{\circledR}$ coatings on a magnesium alloy, Surf. Coat. Technol. 182 (2004) 78-84.

[13]A.G. Rakoch, V.V. Khokhlov, V.A. Bautin, N.A. Lebedeva, Y.V. Magurova, I.V. Bardin, Model concepts on the mechanism of microarc oxidation of metal materials and the control over this process, Protect. Met. 42 (2006) 158-169.

[14]A.K. Sharma, R.U. Rani, K. Giri, Studies on anodization of magnesium alloy for 
thermal control applications, Met. Finish. 95 (1997), 43-51.

[15]S. Verdier, N. van der Laak, S. Delalande, J. Metson, F. Dalard, The surface reactivity of a magnesium-aluminium alloy in acidic fluoride solutions studied by electrochemical techniques and XPS, Appl. Surf. Sci. 235 (2004) 513-524.

[16]R. Arrabal, E. Matykina, T. Hashimoto, P. Skeldon, G.E. Thompson, Characterization of AC PEO coatings on magnesium alloys, Surf. Coat. Technol. 203 (2009) 2207-2220.

[17]N. Alexandre, Microdischarges in aqueous electrolytic and their interaction with materials: the case of plasma electrolytic oxidation (PEO), Universite de Lorraine, Ph.D thesis, 2014.

[18]J.A. Curran. Thermal and mechanical properties of plasma electrolytic oxide coatings, University of Cambridge, Ph.D thesis, 2005.

[19]G.L. Song. Corrosion prevention of magnesium alloys, Woodhead Publishing Limited, (2013), pp. 163-196.

[20]L.S. Wang, C.X. Pan, Q.Z. Cai, B.K. Wei. Study of the heat effect of single steady-state microdischarge during plasma electrolytic oxidation, Acta Physica Sinica, 56(9) (2007) 5341-5446.

[21]W. Robert, Jr. Messler. Principles of welding (processes, physics, chemistry, and metallurgy). Willey-Vch Verlag GmbH \& Co. KgaA, Weinheim, 2004, pp. 344-348

[22]S. Kou. Welding Metallurgy (Second Edition), John Wiley \& Sons, Inc., 2003, pp. $82-96$.

[23]S. Ono, K. Asami, T. Osaka, N. Masuko. Structure of anodic films formed on magnesium, J. Electrochem. Soc. 143 (1996) L62-L63.

[24]A.K. Vijh. Electrochemistry of metals and semiconductors. Marcel Dekker, Inc., New York, 1970, pp. 129-166. 
Table 1. Characterics of different spark periods during SA processing.

\begin{tabular}{lllll} 
& Period I & Period II & PeriodIII & PeriodIV \\
& $(\sim 0-0.3 \mathrm{~min})$ & $(\sim 0.3-2 \mathrm{~min})$ & $(\sim 2-4 \mathrm{~min})$ & $(\sim 4-90 \mathrm{~min})$ \\
\hline Color & Latent sparking & White sparking & Whilte and & Flame-type(soft $)$ \\
& & & Yellow sparking & sparking \\
Sound & Gas evolution & noisy & noisy & quiet \\
Size & Sporadic and tiny & tiny & larger & larger \\
\hline
\end{tabular}

Table 2. Escaping work functions of related element and oxide [24]

\begin{tabular}{llll}
\hline & $\mathrm{Mg}$ & $\mathrm{Al}$ & $\mathrm{Si}$ \\
\hline Pure metal & $3.78 \mathrm{eV}$ & $4.25 \mathrm{eV}$ & - \\
Metal oxide & $3.31 \mathrm{eV}(\mathrm{MgO})$ & $3.9 \mathrm{eV}\left(\mathrm{Al}_{2} \mathrm{O}_{3}\right)$ & $-\left(\mathrm{SiO}_{2}\right)$ \\
\hline
\end{tabular}




\section{Figure Captions}

Figure 1. V-t curve of the SA process during the first 10minutes.

Figure 2. Wave-form transition of current at around a) 2min; b) 3min; c) 4min; d) 10min; e) $25 \mathrm{~min}$; and f) $75 \mathrm{~min}$ into the $\mathrm{SA}$ process ( $\mathrm{X}$ axis for time: $5 \mathrm{~ms} / \mathrm{grid}$, $\mathrm{Y}$ axis for current density: $\left.165 \mathrm{~mA} \cdot \mathrm{cm}^{-2} / \mathrm{grid}\right)$.

Figure 3. Surface morphology micrographs of the thick SA coating. a) SE image; and b) BSE image.

Figure 4. Cross-section images of (a) morphology and related element distribution: (b) $\mathrm{Mg}$; (c) O; (d) Si; and (e) P of the thick SA layer.

Figure 5. Line composition scanning results showing the $\mathrm{P}, \mathrm{Si}, \mathrm{Mg}$, and $\mathrm{O}$ distribution across a SA layer.

Figure 6. Macro-morphology of the unltramicrotomy block after cutting. a) SE image; and b) BSE image.

Figure 7. Interface morphology of the unltramicrotomy block studied by SEM. a) SE image; b) BSE image; c) enlarged SE image; and d) further enlarged SE image.

Figure 8. Interface morphology at two sites of a unltramicrotomy slices observed by TEM.

Figure 9. Nanoindentation test results showing the hardness across the interface region.

Figure 10. XRD spectrum of the SA coating.

Figure 11. Formation mechanism of the thick SA layer. (a) Outer layer formation accompanying by noisy sparking signals; (b) Nanocrystalline oxide seeds formation during the micro-arc plasma process accompanied by soft sparking; and (c) The sub-layer structure: outer layer, middle layer and inner layer. 


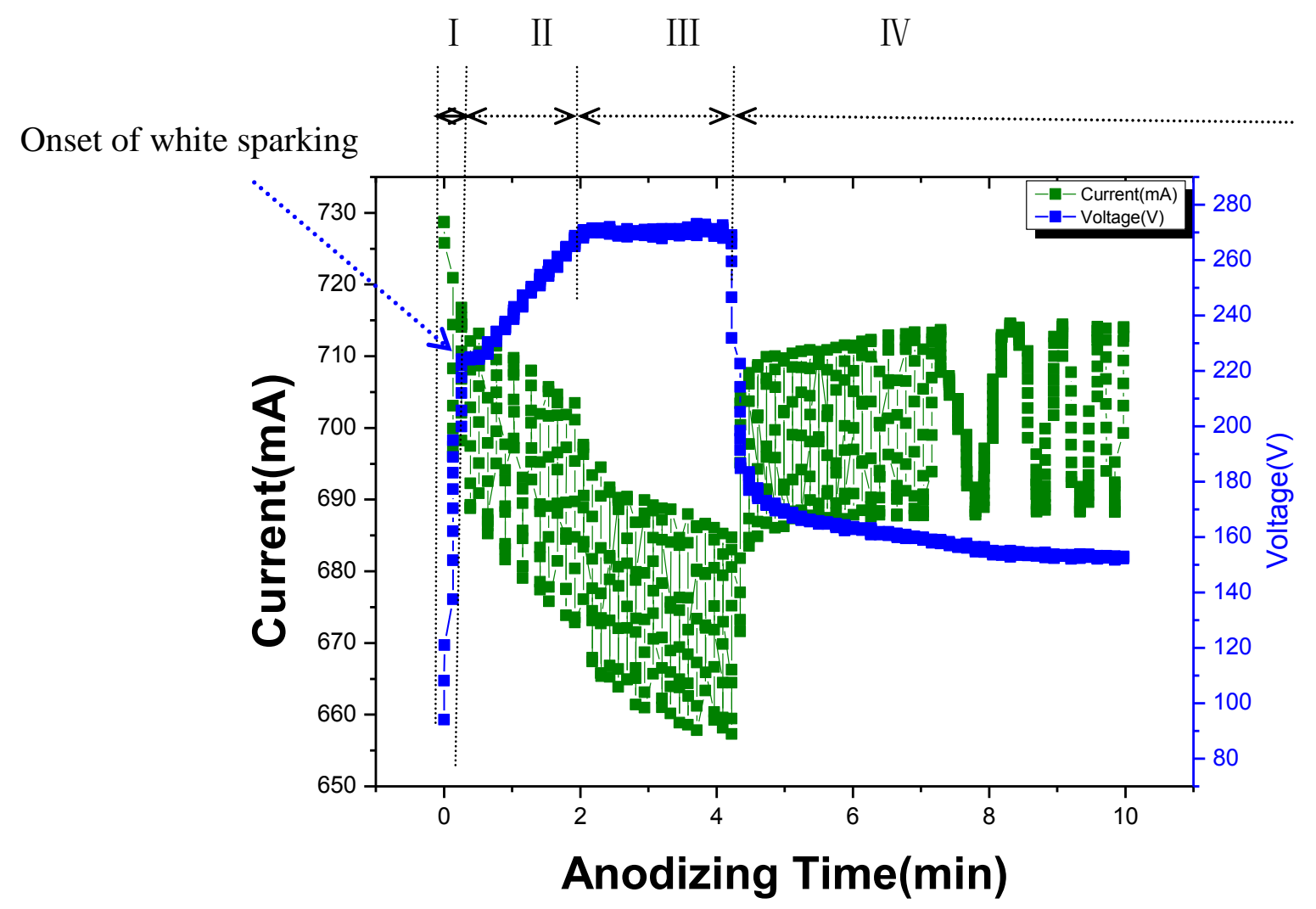

Figure 1. V-t curve transtion for the former 10min anodizing. 

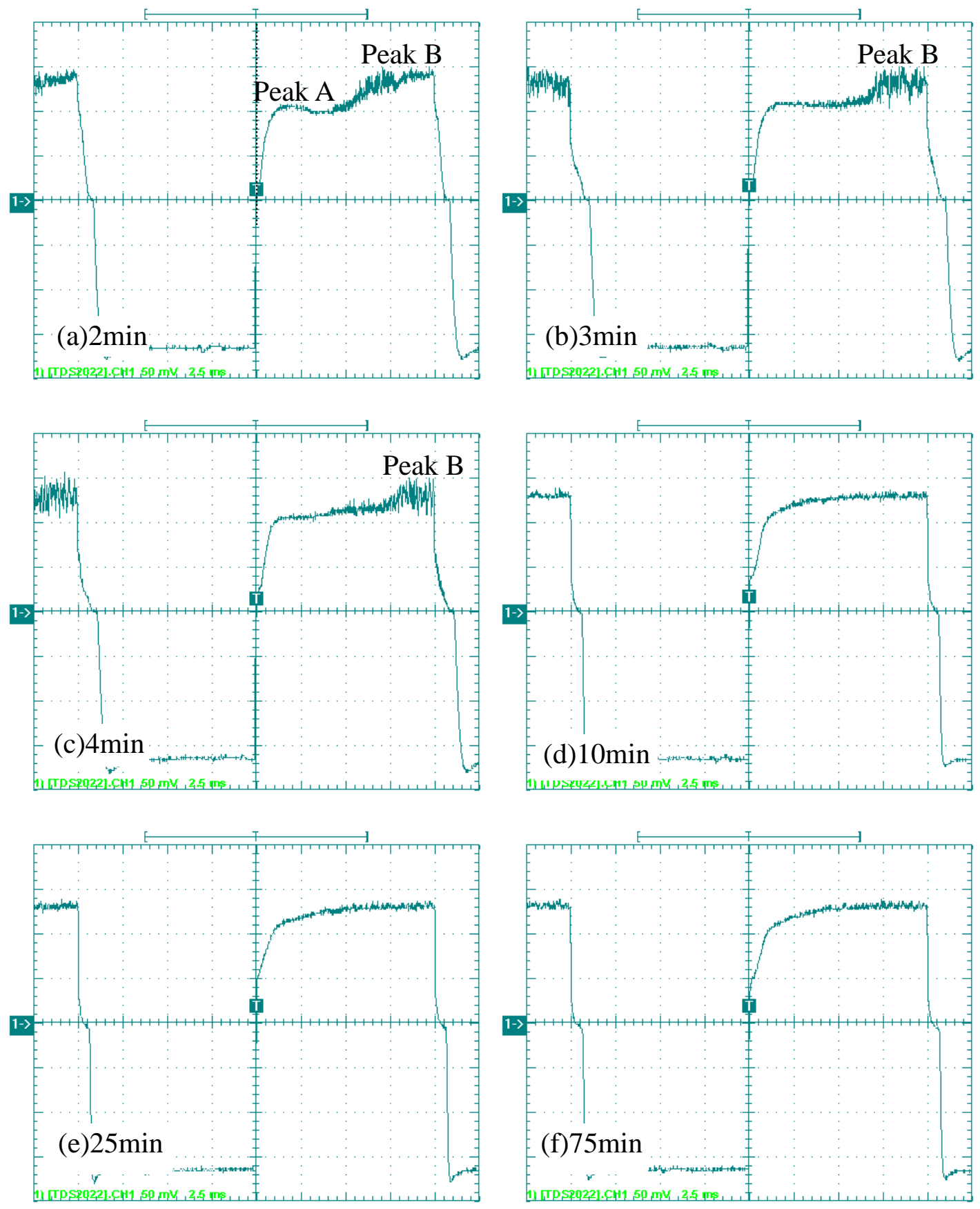

Figure 2. Wave-form transition at different moment a) 2min; b) 3min; c) 4min; d)

10min; e) 25minand f) $75 \mathrm{~min}$ ( $\mathrm{X}$ axis for time: $5 \mathrm{~ms} / \mathrm{grid}$, $\mathrm{Y}$ axis for current density: $165 \mathrm{~mA} \cdot \mathrm{cm}^{-2} /$ grid). 

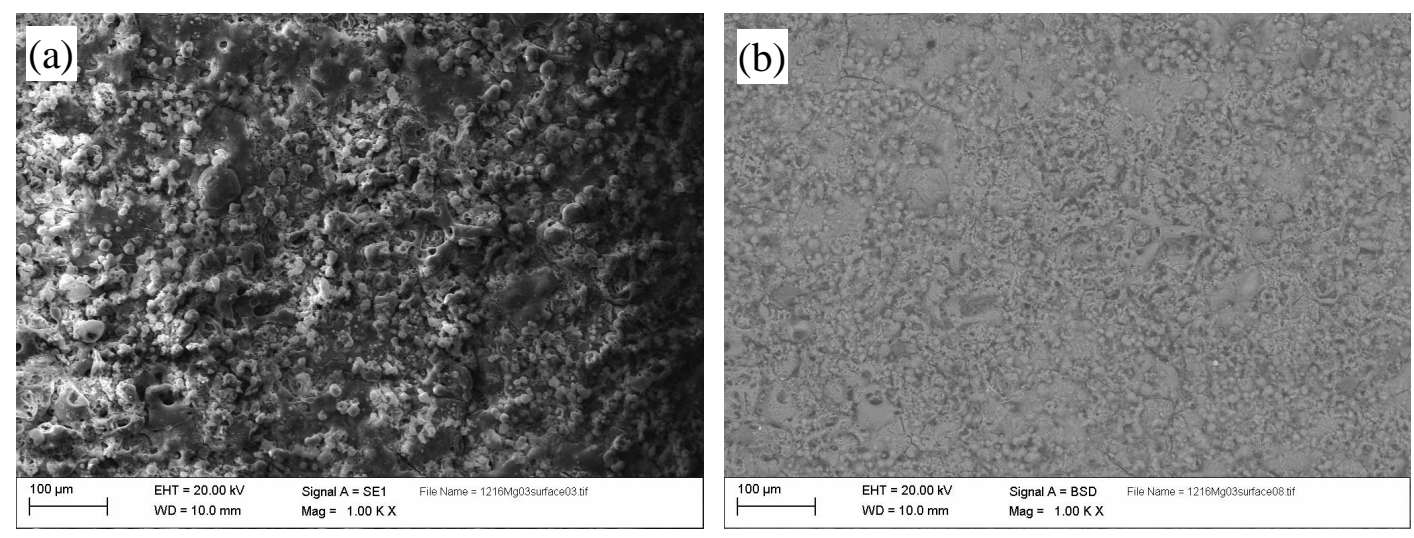

Figure 3. Surface morphology of the thick SA coating a) SE image; b) BSE image. 


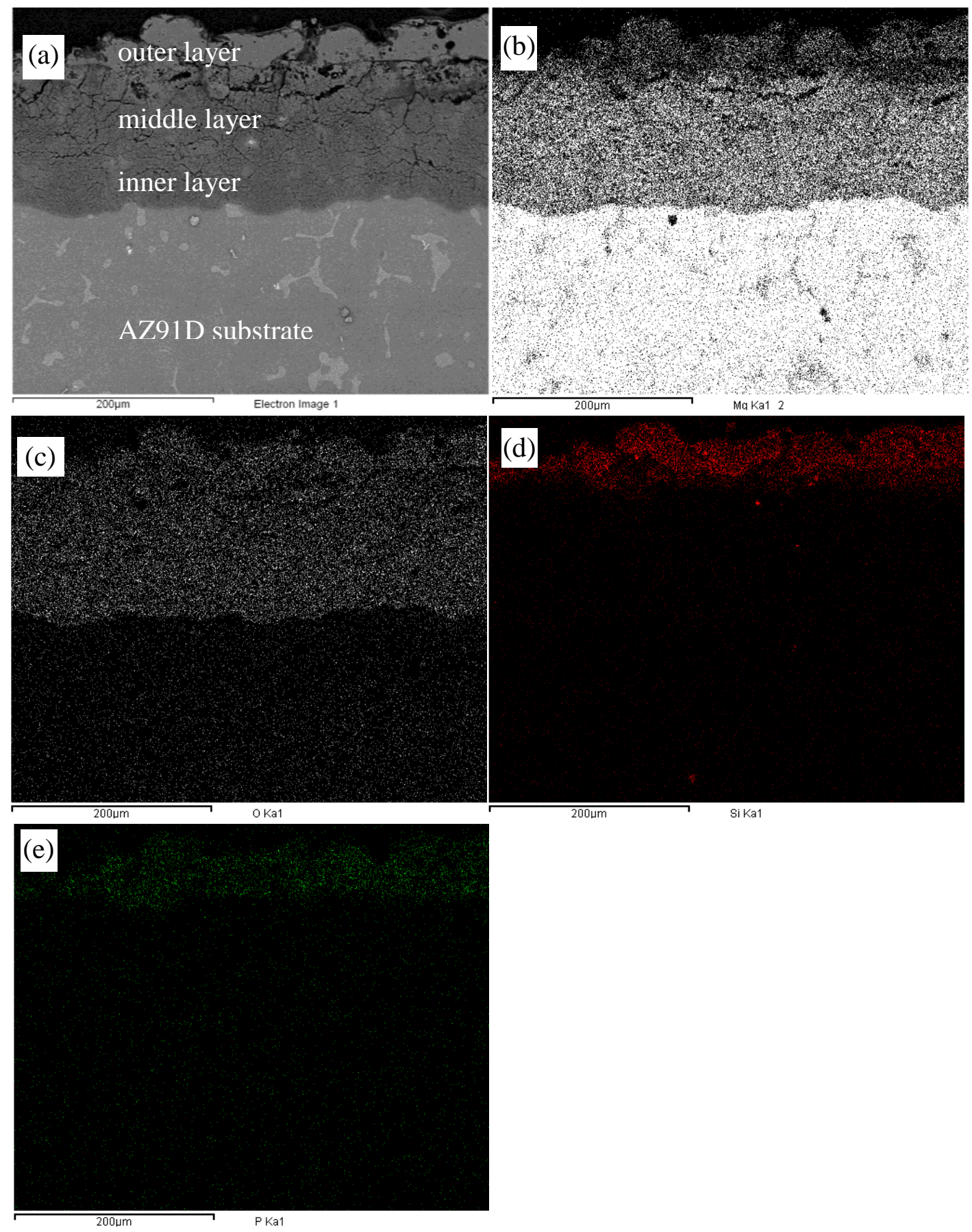

Figure 4. Cross-section morphology (a) and related element distribution: $\operatorname{Mg}(b), O(c)$, Si(d), $\mathrm{P}(\mathrm{e})$ elements respectively. 

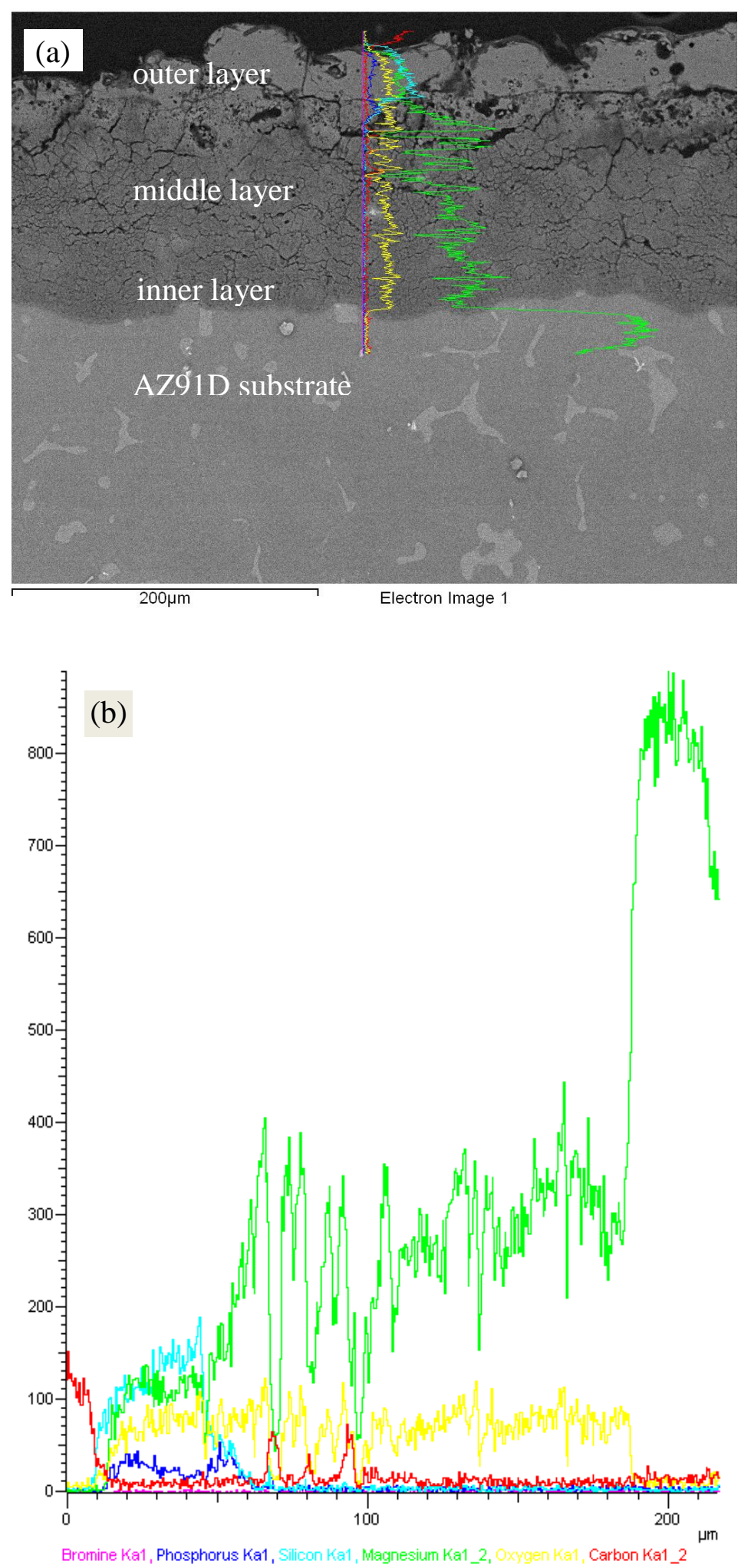

Figure 5. Line scanning result of the related element: $\mathrm{P}, \mathrm{Si}, \mathrm{Mg}, \mathrm{O}$. 


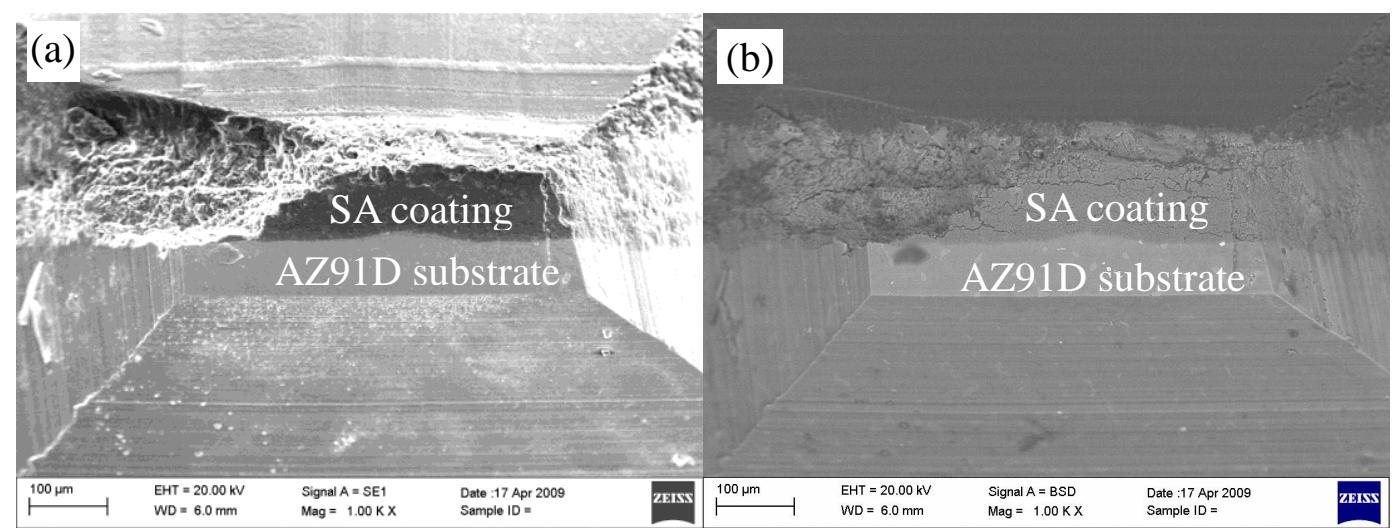

Figure 6. Macromorphology of the unltramicrotomy block after cutting. a) SE image; b) BSE image. 

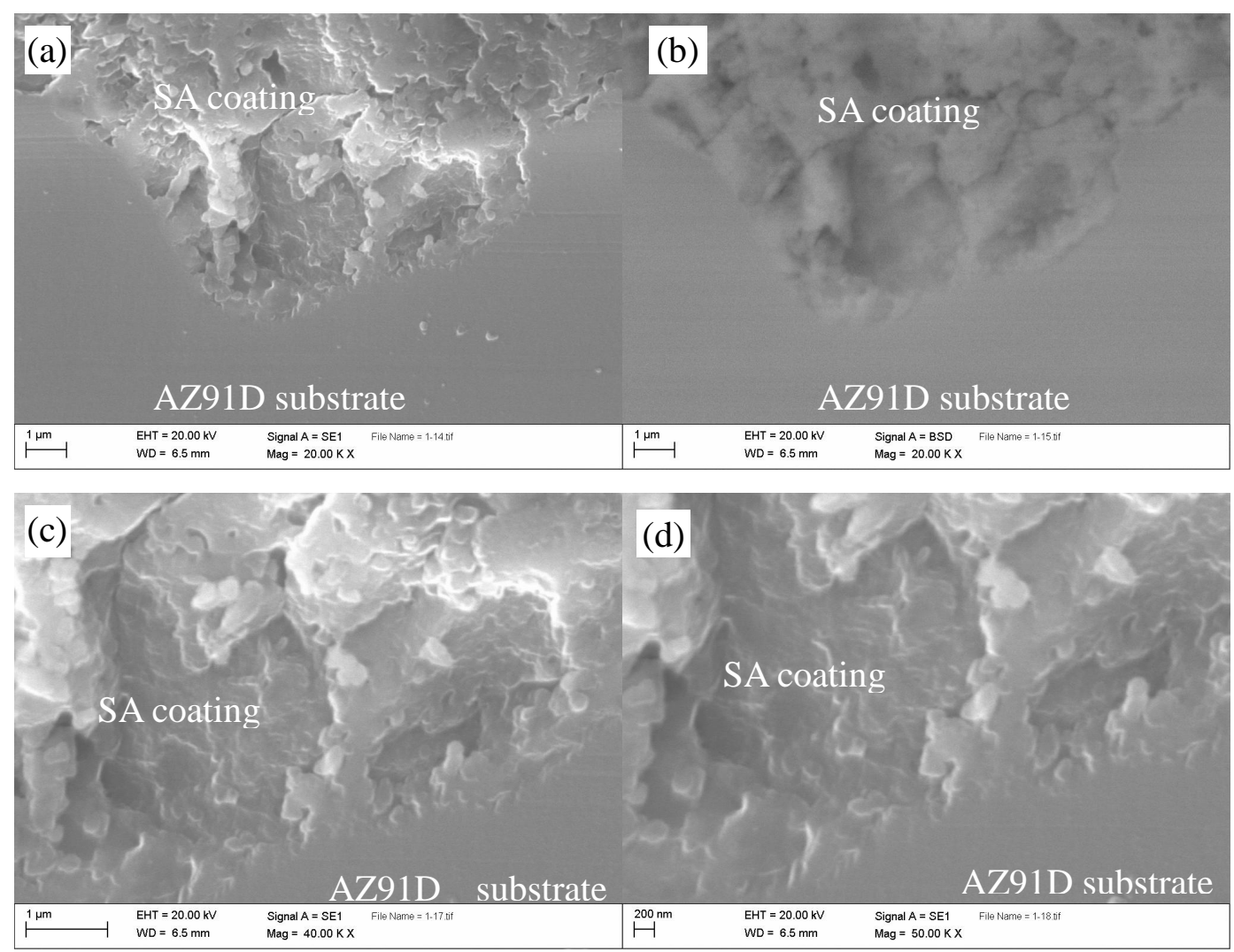

Figure 7. Interface morphology of unltramicrotomy block studied by an SEM. a)

SE image; b) BSE image; c) enlarged SE image; d) further enlarged SE image. 


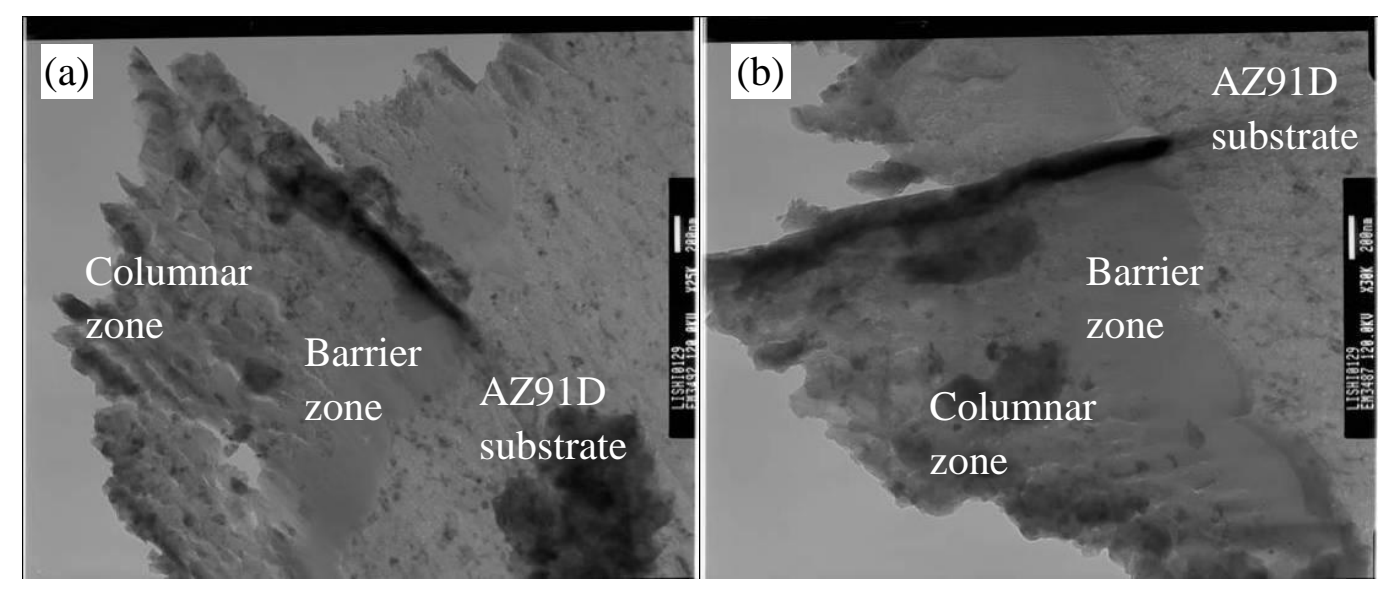

Figure 8. Interface morphology in two sites (a) and (b) of unltramicrotomy slices by TEM. 


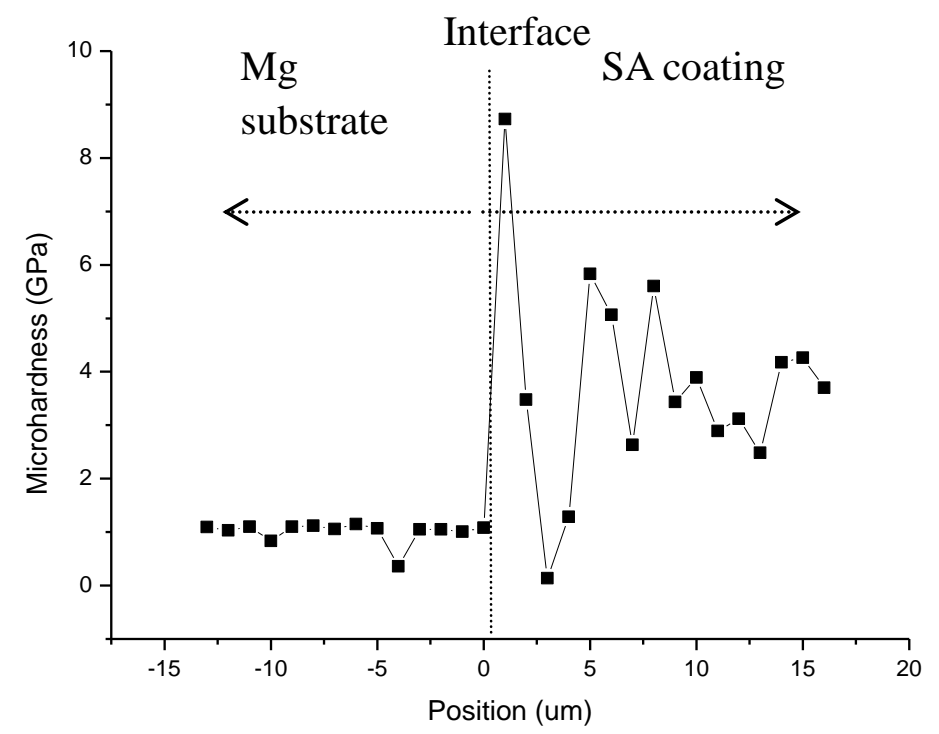

Figure 9. Nanoindentation test for interface region. 


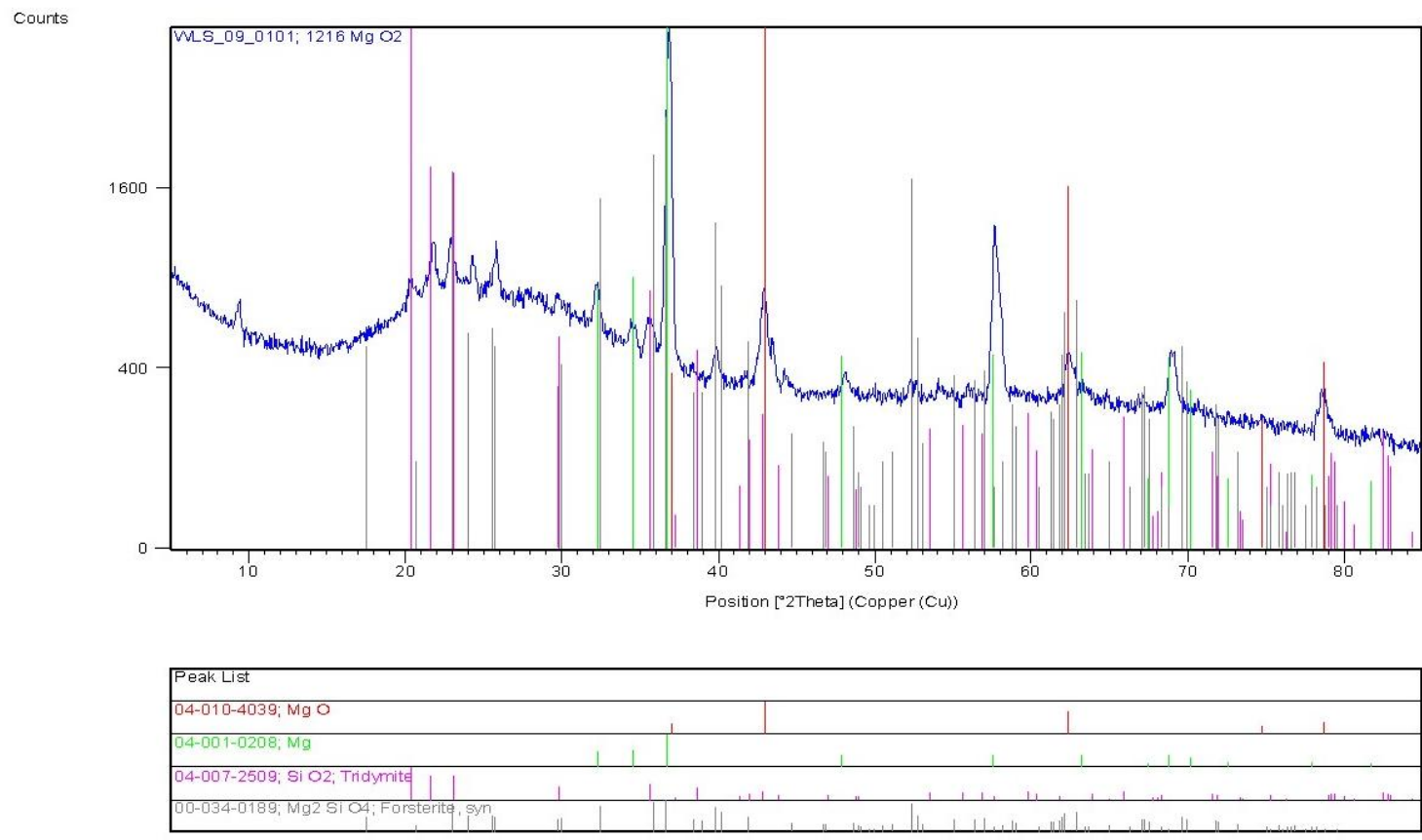

Figure 10. XRD result for the SA coating. 

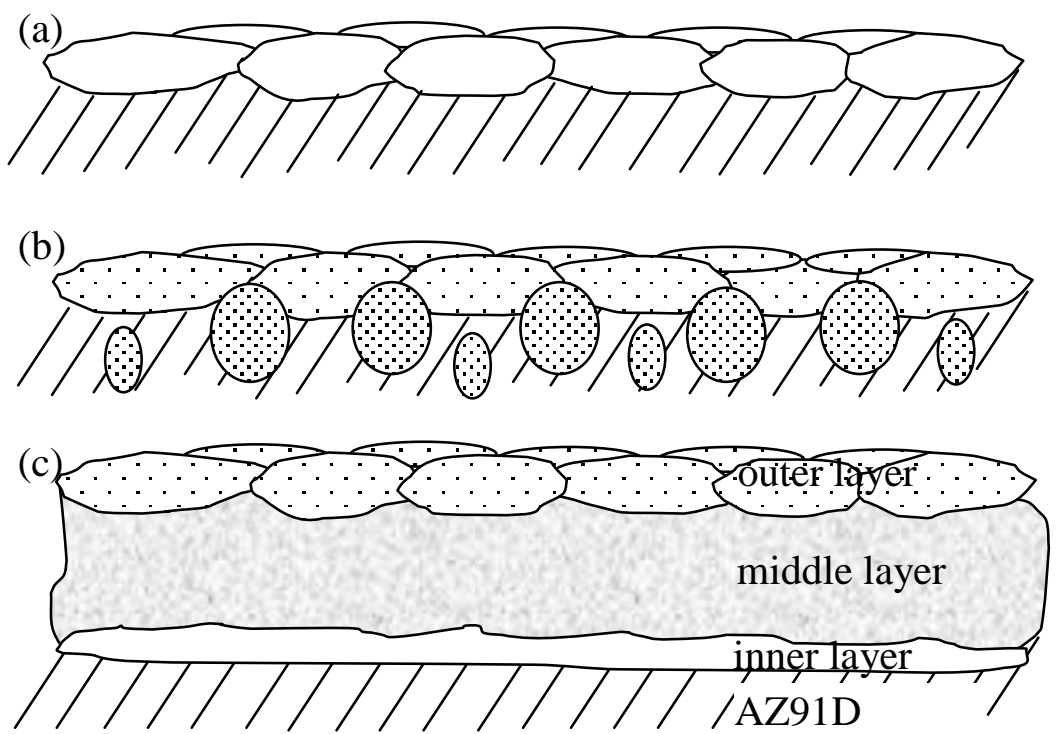

Figure 11. Thick SA coating formation process (not to scale). a) Outer layer formation accompanying with noisy sparking; b) Nanocrystalline oxide seeds for micro-arc plasma accompanying with soft sparking; c) Three sub-layer structure: outer layer, middle layer and inner layer 


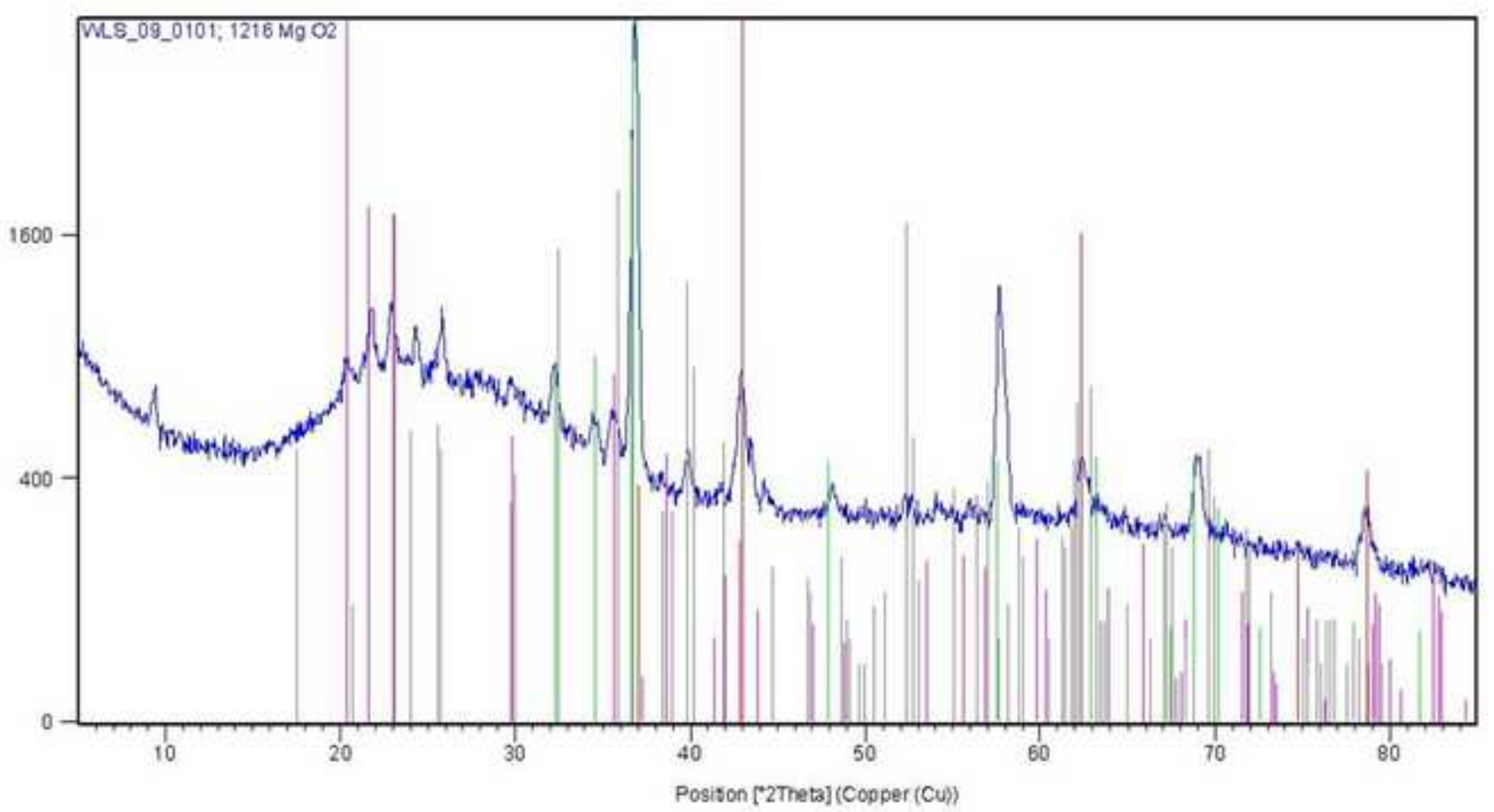

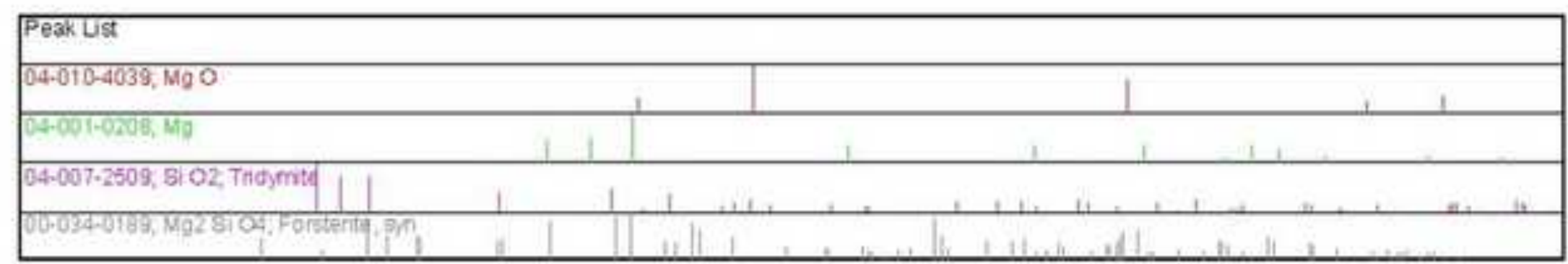

